\title{
Capsizing Probability of an Indonesian RoRo Passenger Ship in Irregular Beam Seas
}

\author{
by Budhi H. Iskandar*, Student Member, Naoya Umeda*, Member, \\ Masami Hamamoto**, Member
}

\begin{abstract}
Summary
The annual capsizing probability was calculated for an Indonesian RoRo passenger ship in Indonesia and Japanese water areas. The calculation method is based on an uncoupled roll equation with the piece-wise linear restoring curves and the existing wave statistics. Numerical results show the quantitative difference between different water areas and positive possibility to determine the minimum metacentric height against capsizing, while they remarks the need for longer wave measurements in Indonesian waters and for the precise prediction of roll damping. Further, the simplified method for the annual capsizing probability is proposed.
\end{abstract}

\section{Nomenclature}

$D_{q} \quad$ : the variance of the forced roll amplitude

$D_{\dot{q}} \quad$ : the variance of the forced roll angular velocity

$f \quad$ : joint probability density of wave height and period

GZ : righting arm

$g \quad$ : gravitational acceleration

$H_{1 / 3} \quad$ : significant wave height

$I_{x x} \quad$ : roll moment of inertia

$J_{x x} \quad$ : added roll moment of inertia

$k_{f 0}, k_{f 1} \quad$ : angle coefficients of partially linear approximation

$M_{w} \quad$ : exciting roll moment due to irregular waves

$m_{A} \quad$ : mathematical expectancy operator for the initial condition of the second range

$n_{\phi} \quad$ : natural roll frequency

$P \quad$ : capsizing probability for a stationary wave state

$P_{\text {annual. }} \quad$ : annual capsizing probability

$P^{*} \quad$ : long term capsizing probability

$q_{a i} \quad$ : amplitude of forced roll motion

$R \quad$ : roll damping coefficient

$S \quad$ : wave spectral density

* Department of Naval Architecture \& Ocean Engineering, Graduate School of Engineering, Osaka University.

** Fukui University of Technology

Received 10 th July 2000

Read at the Autumn meeting 16, 17 th Nov. 2000

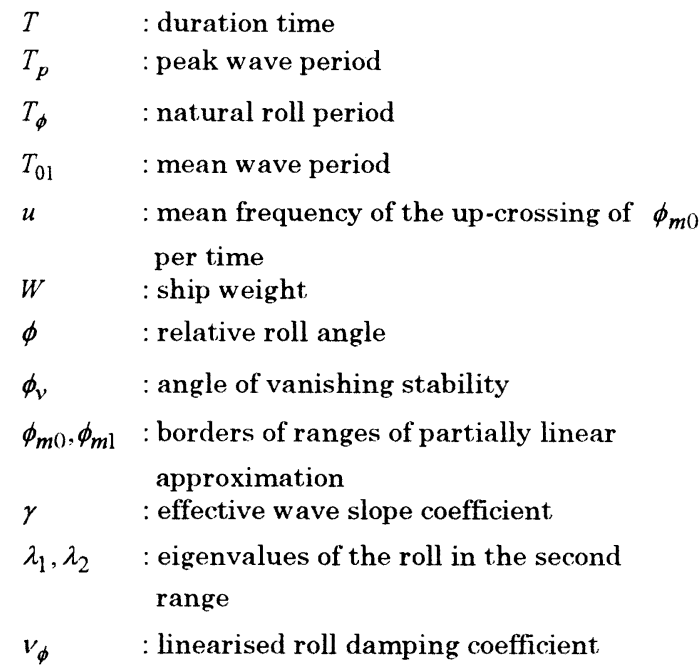

\section{Introduction}

Indonesia is a maritime country with two - third of the state consisted of seawaters. This part (seawaters) has an important role as a transportation media. It is acknowledged that the marine transportation in this country is one of high-risk activities. The safety of marine transportation should be throughout examined.

At present, a RoRo passenger ship has been a necessary means of Indonesian marine transportation. Several capsizing cases of RoRo passenger ship have occurred in Indonesian waters and many people lost their lives and properties as well. Since Indonesia does not have a stability standard until now, establishment of the standard is an urgent issue. Although the International Maritime Organization (IMO) 
recommends stability codes of intact passenger and cargo ships, applicability of such codes to Indonesian ships in Indonesian water areas is still unknown. Indonesian water areas might be more moderate but there are no obvious ways of quantifying the expected degree of danger. In addition, the required risk level for the stability standards should be determined from economical and cultural background of each nations. Therefore, the authors attempt to examine the methodology for establishing stability criteria in the light of capsizing probability, which is the final output from nonlinear ship dynamics under stochastic excitation, such as ocean waves, for comparing with the acceptable risk level.

The general concept of capsizing probability, in other words, risk analysis against capsizing, was explained by Sevastianov ${ }^{1)}$ and Kobylinski ${ }^{2)}$. Here, to realize this concept, it is necessary to rationally calculate capsizing probability in a stationary wave condition by utilizing the reliable mathematical model of ship behaviors. For this purpose, Blocki ${ }^{3)}$, Umeda et al., ${ }^{4-5)}$ Belenky $^{6-7)}$, Nechaev ${ }^{8)}$, Shen and Huang ${ }^{9)}$ and others proposed calculation methods of capsizing probability for several capsizing modes in a stationary sea state and showed some numerical examples for the probability in stationary state. Among them, Belenky ${ }^{6)}$ presented a most rigorous method for calculating capsizing probability in stationary beam waves by use of the piece-wise linear restoring approximation. Because of this approximation, this method requires only calculations based on analytical solutions. And he ${ }^{1(1)}$ recently demonstrated that even with this approximation several nonlinear phenomena known in this ship roll motion, such as bifurcation and chaos, can be properly realized. In spite of these proposals, these calculation methods have not been yet used for the capsizing probability for a long term. Thus, it might be time to examine the applicability of capsizing probability concept by systematically calculating the annual capsizing probability with the above method. As an exception, it should be noted here that Caldwell and Yang ${ }^{11)}$ presented the long term probability in beam seas with the Lyapunov direct method. Because of the nature of the Lyapunov method, their results did not directly take the wave period into account. Thus, the effect of the wave period on the annual capsizing probability remains as also an unsolved problem.

Considering the above situation, the authors intend to examine the applicability of capsizing probability by systematically calculating the annual capsizing probability of an Indonesian RoRo ship drifting in irregular beam seas of Indonesian waters. As well known, a ship running in following and quartering seas can easily capsize than in drifting beam seas. However, the ship master can avoid the situations of running in following and quartering seas simply by stopping the engine. Then the ship may meet only waves from side. Thus, the capsizing probability in beam seas is the primary factor for ship stability and then the information of danger in following and quartering seas can be provided for the ship master. This is the reason why the authors focus on capsizing probability in beam seas in this paper.

\section{Evaluation of the annual capsizing probability}

In this paper, capsizing is explored with the following nonlinear and uncoupled equation of relative roll angle, $\phi$, under stochastic wave excitation, $M_{\mathcal{w}^{\prime}}(t)$.

$$
\left(I_{x x}+J_{x x}\right) \ddot{\phi}+R \dot{\phi}+W G Z(\phi)=M_{w}(t)
$$

Here the restoring arm curve is approximated with piece-wise linear one as follows:

$$
\mathrm{GZ}=\left\{\begin{array}{ccc}
n_{\phi}^{2} \cdot k_{f 0} \phi & \phi \in\left[0 ; \phi_{m 0}\right] & \text { range No. 1 } \\
n_{\phi}^{2} \cdot k_{f 1}\left(\phi_{v}-\phi\right) & \phi \in\left[\phi_{m 0} ; \phi_{m 1}\right] & \text { rangeNo.2 }
\end{array}\right\}
$$

The roll damping coefficient, $v_{\phi}$, is

$$
\nu_{\phi}=\frac{R}{2\left(I_{x x}+J_{x}\right)}=\frac{2}{T_{\phi}}\left(a+b \phi_{m}\right)
$$

where $\mathrm{a}$ and $\mathrm{b}$ are the extinction coefficients from a roll decay test. In the first range, the value of $\phi_{m}$ is assumed to be 10 degree, following practice of the seakeeping and for the second range the value of $\phi_{v}$ is considered as $\phi_{m}$. This is because $\phi_{v}$ can be the maximum roll amplitude without capsizing.

As Belenky ${ }^{6)}$ formulated in his work, the capsizing probability for a ship in a stationary seaway for the duration time. T, can be calculated as the product of the probability of the roll angle for exceeding $\phi_{m i}$ and the probability of diverging behavior in the second range. The details of his method are explained in the literatures ${ }^{(6-7)}$. His final formulae are summarized as follows:

$$
P\left(H_{1 / 3}, T_{01}, T\right)=4\left(1-e^{(-u T)}\right) \Phi\left(\frac{m_{A}}{\sqrt{D_{A}}}\right)
$$

where:

$$
\begin{aligned}
& m_{A}=\frac{-\lambda_{2}\left(\phi_{m()}-\phi_{v}\right)}{\lambda_{1}-\lambda_{2}} \\
& D_{A}=\left(\frac{1}{\lambda_{1}-\lambda_{2}}\right)^{2} D_{\dot{q}} \\
& D_{q}=\frac{1}{2} \sum_{i=1}^{\infty} q_{a i}^{2} \\
& D_{\dot{q}}=\frac{1}{2} \sum_{i=1}^{\infty} \omega_{i}^{2} q_{a i}^{2}
\end{aligned}
$$




$$
\begin{gathered}
\lambda_{1,2}=-v_{\phi} \pm \sqrt{n_{\phi}^{2} k_{f 1}+v_{\phi}^{2}} \\
u=\frac{1}{2 \pi} \sqrt{\frac{D_{\dot{q}}}{D_{q}}} e^{\left(-\frac{\phi_{m 0}^{2}}{2 D_{q}}\right)} \\
q_{a i}=\frac{k_{f 0} n_{\phi}^{2} \gamma \frac{\omega_{i}^{2}}{g}}{\sqrt{\left(k_{f 0} n_{\phi}^{2}-\omega_{i}^{2}\right)^{2}+4 v_{\phi}^{2} \omega_{i}^{2}}} \sqrt{2 S\left(\omega_{i}\right) d \omega_{i}} \\
\Phi(Z)=\frac{1}{\sqrt{2 \pi}} \int_{-\infty}^{z} e^{-\frac{x^{2}}{2}} d x
\end{gathered}
$$

Once the capsizing probability for a stationary wave state is obtained, the annual capsizing probability, $P_{\text {annual }}$, can be evaluated as follows:

$$
P_{\text {annual }}=1-\left(1-P^{*}(T)\right)^{\frac{365 \times 24 \times 3600}{T}}
$$

where

$$
P^{*}(T)=\int_{0}^{\infty} \int_{0}^{\infty} f\left(H_{1 / 3}, T_{01}\right) P\left(H_{1 / 3}, T_{01}, T\right) d H_{1 / 3} d T_{01}
$$

Similar formulae have been used in several literatures 12-13).

\section{Results and discussion}

\subsection{Sampled ship details}

A typical Indonesian RoRo passenger ship, serving for the transportation between main islands of Indonesia, was used for calculation in this paper. Her principal particulars are shown in Table 1.

Table 1. Principal particulars of an Indonesian RoRo passenger ship under the design condition

\begin{tabular}{|l|l|l|}
\hline \multicolumn{2}{|l|}{ Items } & Ship \\
\hline Length & Lpp (m) & 40.0 \\
\hline Breadth & B (m) & 11.0 \\
\hline Depth & D (m) & 7.00 \\
\hline Draft & d (m) & 1.90 \\
\hline Block coefficient & Cb & 0.75 \\
\hline Metacentric height & GM (m) & 1.28 \\
\hline Natural roll period & T $\phi($ sec.) & 9.51 \\
\hline
\end{tabular}

She, under the design condition, almost critically complies with the intact stability code of $\mathrm{IMO}^{14)}$, as shown in Table 2. A positive sign, + , in the last column means that the ship complies with each requirement. The requirement for the angle for the maximum $\mathrm{GZ}$ is almost identical to the designed value of the ship.
Table 2. The comparison between IMO criteria and the ship

\begin{tabular}{|c|c|c|}
\hline Norm & IMO code & The ship \\
\hline A & 0.055 m.rad & $0.157(+)$ \\
\hline B & 0.09 m.rad & $0.223(+)$ \\
\hline C & $0.03 \mathrm{~m} . \mathrm{rad}$ & $0.066(+)$ \\
\hline D & $0.20 \mathrm{~m}$ & $0.451(+)$ \\
\hline E & $>25^{\circ}$ & $26(+)$ \\
\hline F & $\geq 0.15 \mathrm{~m}$ & $1.28(+)$ \\
\hline
\end{tabular}

Remarks:

A : Area under the GZ curve until $30^{\circ}$.

$B$ : Area under the GZ curve until $40^{\circ}$.

C : Area under the GZ curve between $30^{\circ}-40^{\circ}$.

$\mathrm{D}$ : Maximum righting arm.

$\mathrm{E}$ : Angle of maximum stability.

$\mathrm{F}$ : Metacentric height.

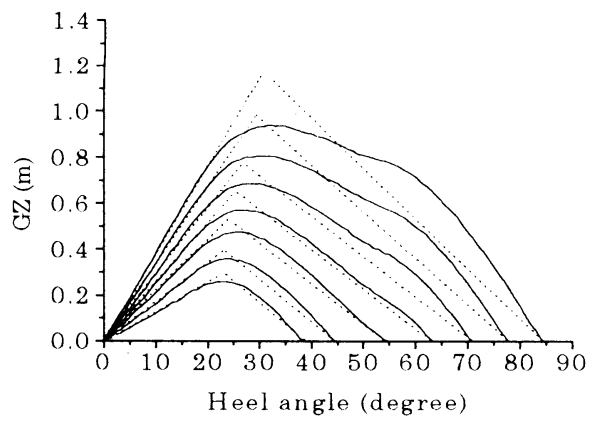

Fig. 1. GZ curves of the ship for different GM, ranging from $0.75 \mathrm{~m}$ to $2.25 \mathrm{~m}$, with their piece-wise linear approximations

Because of the roll decay data are not available for this ship, the extinction coefficients, $a$ and $b$, are assumed to be identical to the ones recommended as standard values for a ship with bilge keels by Watanabe ${ }^{15)}$. That is, $a$ is 0.025 and $b$ is 0.02 . Similarly, the effective wave slope coefficient, $\gamma$, is assumed to be 1.0 .

\section{$3.2 \mathrm{GZ}$ curves and piece-wise approximation}

Since the restoring arm curve is generally nonlinear, it is necessary to approximate it with the piece-wise linear one. In this paper the straight line in the first range is provided by locally linearised at the upright position and that in the second range is adjusted to keep the dynamic stability at $\phi_{v}$ unchanged. Thus, the metacentric height, the stability range and the dynamic stability at $\phi_{v}$ are the same as the original restoring area curve. 

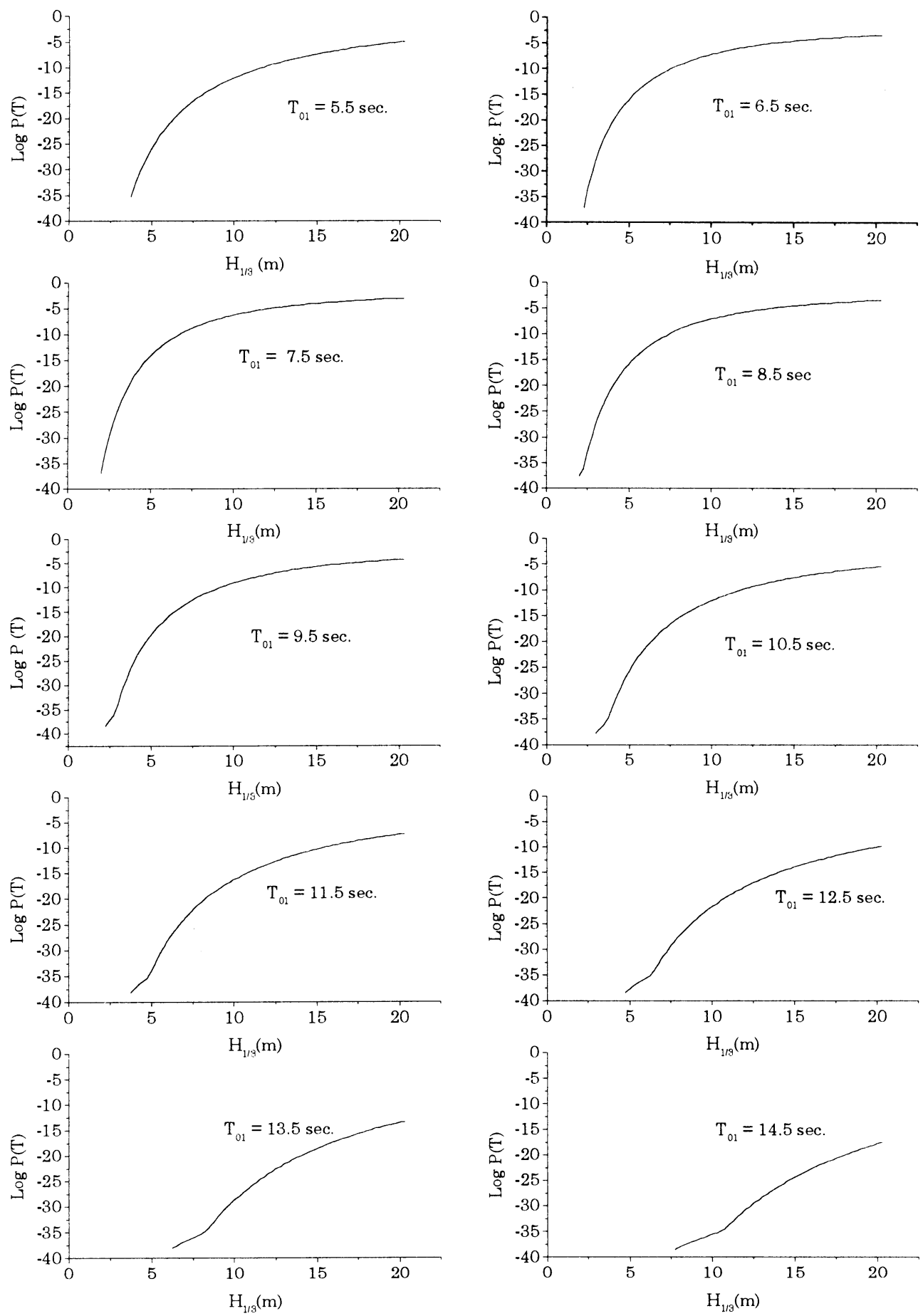

Fig. 2. Capsizing probability of the ship for different stationary waves at GM of $1.28 \mathrm{~m}$. 
These three indices are the most crucial for the ship stability under a periodic external moment although the maximum value of $\mathrm{GZ}$, responsible for the stability under a constant external moment, is not the same. Fig. 1 shows the GZ curves for different GM values for the ship with the piece-wise linear approximation.

\subsection{Capsizing probability for a stationary wave state}

Capsizing probability was calculated for stationary wave states having constant wave heights and wave periods with an appropriate wave spectrum shape. In this paper, the ITTC (1978) spectrum is assumed as standard, which is defined as follows:

$$
S(\omega)=A \omega^{-5} e^{\left(-B \omega^{-4}\right)} \quad \mathrm{m}^{2} . \mathrm{sec} .
$$

where,

$$
\begin{aligned}
& A=173 H_{1 / 3} T_{01}^{-4} \\
& B=691 T_{01}^{-4} \\
& T_{p}=1.295 T_{01}
\end{aligned}
$$

because recent wave measurements in Indonesian water area ${ }^{16)}$ show that higher waves can be fitted with the ITTC (1978) spectrum while lower waves are often different from the ITTC one. Throughout this paper, the duration, $\mathrm{T}$, is assumed to be 1200 seconds.

Fig. 2 shows an example of the capsizing probability calculated for several stationary waves. When the significant wave height increases, the capsizing probability increases. Maximum value of capsizing probability among these figures appears in the cases of the mean wave periods ranging 6.5 and 9.5 seconds. As shown here, the capsizing probability depends not only the significant wave height but also the mean wave period. Since the natural roll period for GM $=1.28 \mathrm{~m}$ is 9.5 seconds, the effect of mean wave period is presumed to be due to the harmonic resonance. To clarify this further, effect of GM on the capsizing probability for a stationary wave state was calculated. As shown in Fig. 3, the capsizing probability has a peak near the case in which the natural roll period is identical to the mean wave period. This results demonstrate that the harmonic resonance should be taken into account for the capsizing probability prediction.

\subsection{Comparison of capsizing probability in Indonesia and Japanese water area}

As a next step, the annual capsizing probability in Indonesian water areas and Japanese water area were compared. There are two areas in Indonesian water i.e. area No. 61 (Indian Ocean; off the western part of Sumatra Island) and area No. 62 (South China Sea, off the eastern part of Sumatra Island), and around Japanese Isles.

The wave statistics for the Indonesian water areas, area No. 61 and 62, is based on Global Wave Statistic (GWS) by the British Maritime Technology $\operatorname{Ltd}^{17)}$, and that for the Japanese water areas is on

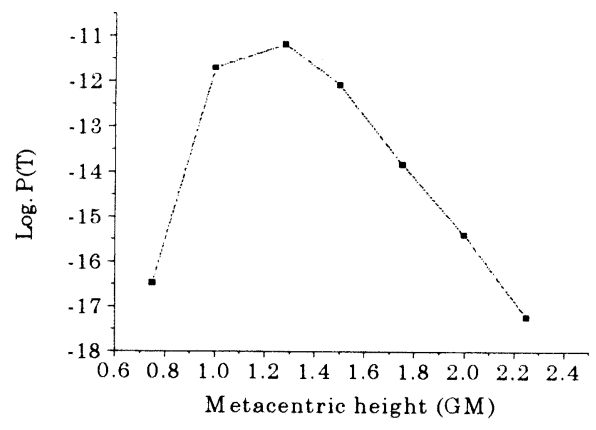

Fig. 3. The value of capsizing probability for different metacentric heights in a stationary wave state with the significant wave height of 5.5 meters and the mean wave period of 9.5 seconds

the wave observation database by Ship Research Institute $(\mathrm{SRI})^{18)}$. Geographically, area No. 61 lies between $0^{\circ}-10^{\circ} \mathrm{N}$ and $80^{\circ} \mathrm{E}-100^{\circ} \mathrm{E}$, the area No. 62 lies between $0^{\circ}-14^{\circ} \mathrm{N}$ and $99^{\circ} \mathrm{E}-117^{\circ} \mathrm{E}$ and the Japanese Isles waters area lies between $30^{\circ} \mathrm{N}-50^{\circ} \mathrm{N}$ and $120^{\circ} \mathrm{E}-150^{\circ} \mathrm{E}$. In the area No. 61 the significant wave heights range between 0.5 to 5.5 meters and the mean-wave periods range between 4.360 to 11.445 seconds. In the area No. 62 the significant wave heights range between 0.5 to 6.5 meters and the mean-wave periods range between 4.360 to 10.355 seconds. In the Japanese waters the significant wave heights range between 0.5 to 15.25 meters and the mean-wave periods does between 2.5 to 14.5 seconds.

It is noteworthy that the statistics in GWS filtered off the wave observations with occurrence frequency less than $1 / 1000$. Thus, for a comparison sake, we calculated the capsizing probability for the Japanese waters also by excluding smaller frequency from the SRI database.

The result of calculation is shown in Fig. 4. The values indicate that the capsizing probability in Indonesian waters is smaller than that in Japanese waters even with the filtering taken into account. Among the Indonesian waters, the capsizing probability of the area No. 62 belonging to South China Seas is larger than the area No. 61 belonging to Indian Ocean.

The smallest values of capsizing probability, especially for Indonesian water area, occur at GM value of 0.75 meters. Here, since the natural roll period becomes much longer than the existing wave periods, the roll angel is calculated as so small. Of course, this does not mean that smaller GM can lead to safety against capsizing. Smaller GM usually makes the maximum GZ value smaller. Thus, the ship with smaller GM can easily capsize by even smaller heel moment, that does not change in time, such as a cargo shift. Apart from that such smaller GM range, larger GM guarantees smaller annual capsizing probability. Thus, it is possible to determine the minimum GM as a stability criterion by specifying the acceptable risk level. 


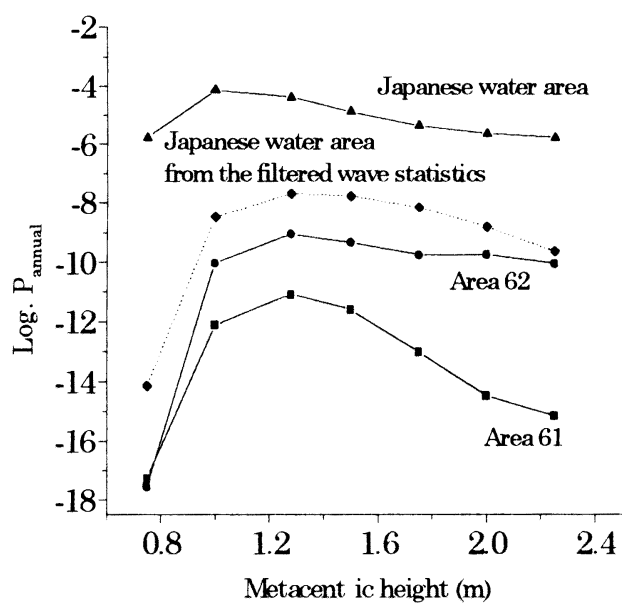

Fig. 4. The annual capsizing probability in Indonesian and Japanese water areas

The significant difference of annual capsizing probability in Japanese waters between the original and filtered wave statistics indicates that the real annual capsizing probability in Indonesia waters might be larger, to some extent, than the calculated one in this figure. Also, we can say that high waves with very small probability can govern the annual capsizing probability. Thus the wave measurement for ship stability should be executed as long as possible.

The importance of heavy but rare waves provides us a chance to develop a simplified method. If we can select such important waves in advance, tedious computation of Eq. (6) can be avoided. Thus the authors propose here the following simplified formulae:

$P^{*}(T) \approx f\left[\left(H_{1 / 3}\right)_{\max }^{*}, T_{\phi} / 1.295\right] P\left[\left(H_{1 / 3}\right)_{\max }^{*}, T_{\phi} / 1.295, T\right] \Delta H_{1 / 3} \Delta T_{01}$

where $\left(H_{1 / 3}\right)_{\max }^{*}$ is the maximum of significant wave heights for the mean wave period given by $T_{\phi} / 1.295$.

This means that the worst wave state for ship stability has the wave peak period of the ship natural roll period and the maximum significant wave height for the relevant wave period.

As shown in Fig. 5, the comparison between the direct and simplified methods demonstrates good agreement for Japanese waters and acceptable one for Indonesian waters. Thus the simplified method proposed here can be used for practical use. Similar methods for long term distribution of linear responses have been published so far ${ }^{19)}$.

For applying the methodology used here to development of a stability criterion, it is necessary to examine sensitivities of ship parameters as well as wave statistics. In this paper, as one of the ship parameters, effect of the roll damping on the annual capsizing probability was calculated.

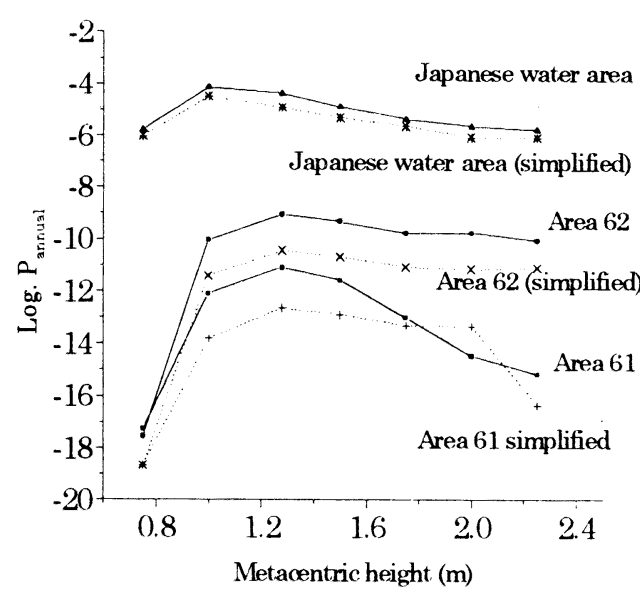

Fig. 5. Comparison of the annual capsizing probability between the proposed simplified method and direct method

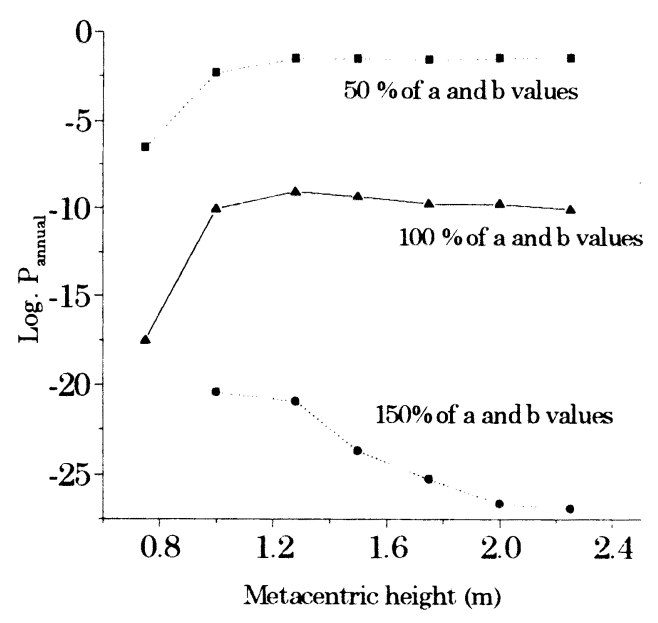

Fig. 6. Comparison of the annual capsizing probability of the ship with different roll damping coefficients in Area 62

Considering the spectrum of roll damping distribution for various hull form, we calculated the annual capsizing probability for $50 \%$ and $150 \%$ of the extinction coefficients of roll damping, $a$ and $b$. As shown in Fig. 6, the effect of roll damping is so significant. Thus, it should be noted that the prediction of the roll damping up to large angle is essential for establishing reliable stability criteria. 


\section{Concluding remarks}

The capsizing probability of the Indonesian RoRo passenger ship, complying with the IMO criteria under her design condition, has been calculated by the piece-wise linear approximation and the existing wave statistics. The following conclusions can be drawn from this work:

1. The annual capsizing probability for Indonesian water areas is lower than in Japanese water area.

2. If the acceptable risk level is specified, the minimum required metacentric height can be determined with the annual capsizing probability calculated for different metacentric heights.

3. The heavy but rare waves can be responsible for the annual capsizing probability.

4. The simplified method to estimate the annual capsizing probability was proposed.

5. The annual capsizing probability significantly depends on the roll damping.

\section{Acknowledgements}

This work is supported by the Ministry of Education, Science, Culture and Sports of Japan through the Japan Society for Promotion of Science (JSPS), and partly from the Grant-in-Aid for Scientific Research. The authors would like to acknowledge the support of their project leaders, Professor K. Kose (JSPS) and Professor K. Saito (Grant-in-Aid) which both of them are from Hiroshima University.

\section{References}

1) Sevastianov, N. B.: An Algorithm of Probabilistic Stability Assessment and Standards, Proceedings of the $4^{\text {th }}$ International Conference on Stability of Ships and Ocean Vehicles, Melbourne, Vol. 5 , (1994).

2) Kobylinski, L., Rational Stability Criteria and Probability of Capsizing, Proceedings of the International Conference on Stability of Ships and Ocean Vehicles, Glasgow, (1975).

3) Blocki, W., Probability of Non-Capsizing of a Ship as a Measure of Her Safety, Proceedings of the $3^{\text {rd }}$ International Conference on Stability of Ships and Ocean Vehicles, Gdansk, Vol. 1, pp.143-149, (1986).

4) Umeda, N. and Yamakoshi, Y., Probability of Ship Capsizing due to Pure Loss of Stability in Quartering Seas, Naval Architecture and Ocean Engineering, Vol. 30, pp.73-85, (1991).

5) Umeda, N., Ikeda, Y. and Suzuki, S., Risk Analysis Applied to the Capsizing of High-Speed Craft in Beam Seas, Proceedings of the $5^{\text {th }}$ International Symposium on the Practical Design of Ships and Mobile Units, New Castle upon Tyne, Vol.2, pp.1131-1145, (1992)

6) Belenky, V.L., Capsizing Probability Computation Method, Journal of Ship Research, Vol. 37, No. 3, pp. 200-207, (1993)
7) Belenky, V. L., Analysis of Probabilistic Balance of IMO Stability Regulation by Piece-Wise Linear Method, Marine Technology Transactions Polish Academy of Sciences, Vol. 6, pp. 5-55, (1995).

8) Nechaev, Y. I., On Probability of Ship Capsizing in a Seaway Estimation, Proceedings of the Sevastianov Symposium, Kaliningrad, Vol. 1, No. 4, p.1-9, (1995)

9) Shen, D. and Huang, X., The Study of Lasting Time Before Capsize of a Ship Under Irregular Wave Excitation, Proceedings of the $7^{\text {th }}$ International Conference on Stability of Ships and Ocean Vehicles, Launceston, Vol. B, pp.710723. (2000).

10) Belenky, V.L., Piece-wise Linear Approach to Nonlinear Ship Dynamics, Proceedings of the $4^{\text {th }}$ International Stability workshop, St. John's, (1998)

11) Caldwell, J.B. and Yang, Y.S., Risk and Reliability Analysis Applied to Ship Capsize -A Preliminary Study-, Proceedings of the International Conference on the Safeship Project: Ship Stability and Safety, the Royal Institution of Naval Architects, London, (1986).

12) Dahle, E.A. and Myrhaug, D., Capsize Risk of Fishing Vessels, Ship Technology Research, Vol. 43, pp. 164-171. (1996)

13) McTaggart, K., Ongoing Work Examining Capsize Risk of Intact Frigates Using Time Domain Simulation, Proceeding of the $4^{\text {th }}$ International Stability Workshop, St. John's, (1998).

14) International Maritime Organization (IMO), Code on Intact Stability for All Types of Ships Covered by IMO Instruments, Resolution A.749(18), (1995).

15) Watanabe,Y., Theory on Ship Roll Problem (Part I - On The Free Rolling -), Lectures of Prof. Y. Watanabe, Vol. 1, Hitachi Zosen, p.285, (1973). (in Japanese)

16) Iskandar, B.H., Spectral Analysis of Measured Data in Indonesian Water Areas, Internal Report, Osaka University, (1999).

17) Hogben, N., Dacunha, N.M.C., and Olliver, G.F., Global Wave Statistics, British Maritime Technology, (1996).

18) Watanabe, I., Tomita, H. and Tanizawa, K., Winds and Waves of the North Pacific Ocean 1974 - 1998, Ship Research Institute, (1992).

19) Mano, H. and Ueno, H., A Simplified Estimation of Long-Term Distributions of Random Variables Induced by Ocean Waves, and a Study on the Influences of Operating Conditions on the Extremes, Journal of the Society of Naval Architecs of Japan, Vol. 132, pp. 235-247, (1972), (in Japanese). 